\title{
SISTEMA DE MONITORAMENTO DE TEMPERATURA USANDO O ARDUINO
}

\author{
Natan Bittencourt ${ }^{1}$; Álvaro Alves ${ }^{2}$ \\ 1. Bolsista PROBIC, Graduando em Física, Universidade Estadual de Feira de Santana, e-mail: \\ natanbittencourt@outlook.com \\ 2. Orientador, Departamento de Física, Universidade Estadual de Feira de Santana, e-mail: \\ asa@uefs.br
}

PALAVRAS-CHAVE: Arduino, Python, termopar.

\section{INTRODUÇÃO}

Existem diversas técnicas para a fabricação de filmes finos. Entre elas, a técnica de spray pyrolysis se destaca por ser a mais simples e barata, dispensando substratos e produtos químicos de alta qualidade. Um equipamento de spray pyrolysis possui uma montagem simples, consistindo de um porta-substrato equipado com um resistor de aquecimento e com um sensor e controlador de temperatura; um substrato para a deposição dos filmes, um atomizador para a pulverização de uma solução salina de metal sobre o substrato, além de uma câmara de vidro com sistema de evacuação.

Segundo Perednis \& Gauckler (2005), na técnica de spray pyrolysis, a temperatura da superfície do substrato é o parâmetro mais influente na determinação da estrutura e das propriedades dos filmes. Isso foi verificado em muitos estudos, como por exemplo, na fabricação de filmes de óxido de índio dopado com flúor (Mirzapour et. al, 1994) e em filmes de zircônio dopados com térbio e estabilizados com ítrio (Stelzer \& Schoonman, 1996).

Ferreira (2005) observou em seu trabalho que a temperatura ideal do substrato para se obter filmes de brometo de tálio (TlBr) com qualidade satisfatória, feitos a partir de solução saturada, deve ser de $100^{\circ} \mathrm{C}$. Nesse caso, sensores de temperatura baratos, acessíveis e de fácil uso como o LM35 (TI, 1999) podem ser utilizados para o monitoramento da temperatura do sistema. Porém, Oja et. al (2004), obtiveram filmes finos cristalinos de dióxido de titânio $\left(\mathrm{TiO}_{2}\right)$ à uma temperatura de $500^{\circ} \mathrm{C}$. Nessas situações, somos obrigados a usar sensores capazes de medir temperaturas relativamente altas, como o termopar tipo $\mathrm{K}$, juntamente com algum condicionador de sinal como o MAX6675 (Maxim Integrated, 2002).

Neste trabalho será apresentado um sistema de software e hardware de monitoramento de temperatura usando o Arduino e sensores termopares na montagem do projeto, e as linguagens $\mathrm{C}++$ e Python na elaboração das instruções para execução das aplicações.

\section{MATERIAL E MÉTODOS OU METODOLOGIA (ou equivalente)}

A montagem experimental consistia num computador de mesa; para desenvolver os algoritmos de controle, uma protoboard; para auxiliar na montagem do projeto, uma placa Arduino Mega; para executar os algoritmos, fios jumper; para fazer as ligações, e seis sensores termopar tipo K com condicionador de sinal; para aquisição e digitalização dos sinais elétricos.

A linguagem de programação Python foi utilizada para a criação dos algoritmos, por ser mais robusta e de sintaxe mais simples. Ela contém uma gama de bibliotecas de arquivos que podem ser implementadas numa variedade de fins. Para tanto, ao longo da pesquisa, foi usada a IDE padrão do Python. Entre as várias bibliotecas utilizadas, as mais importantes são a pySerial e a Matplotlib. A primeira delas serve para realizar a comunicação serial com o Arduino, enquanto a última é usada para gerar interfaces gráficas. 


\section{RESULTADOS E/OU DISCUSSÃO (ou Análise e discussão dos resultados)}

Aproveitando-se dos diversos recursos da biblioteca Matplotlib, foi elaborada uma interface gráfica para a exibição, em tempo real, dos dados de temperatura em função do tempo, de uma quantidade arbitrária de sensores termopares.

$\mathrm{O}$ experimento mais relevante para testar o funcionamento do sistema foi realizado com o circuito elétrico de uma cafeteira. O sistema era constituído simplesmente de uma base metálica, um resistor de aquecimento e um termostato. A base de aquecimento foi perfurada em diversos pontos e em cada furo foi inserido um sensor. Assim que o circuito foi ligado à rede elétrica, começou-se a monitorar a temperatura de cada sensor. Foi observado que a temperatura na superfície da base não variava uniformemente.

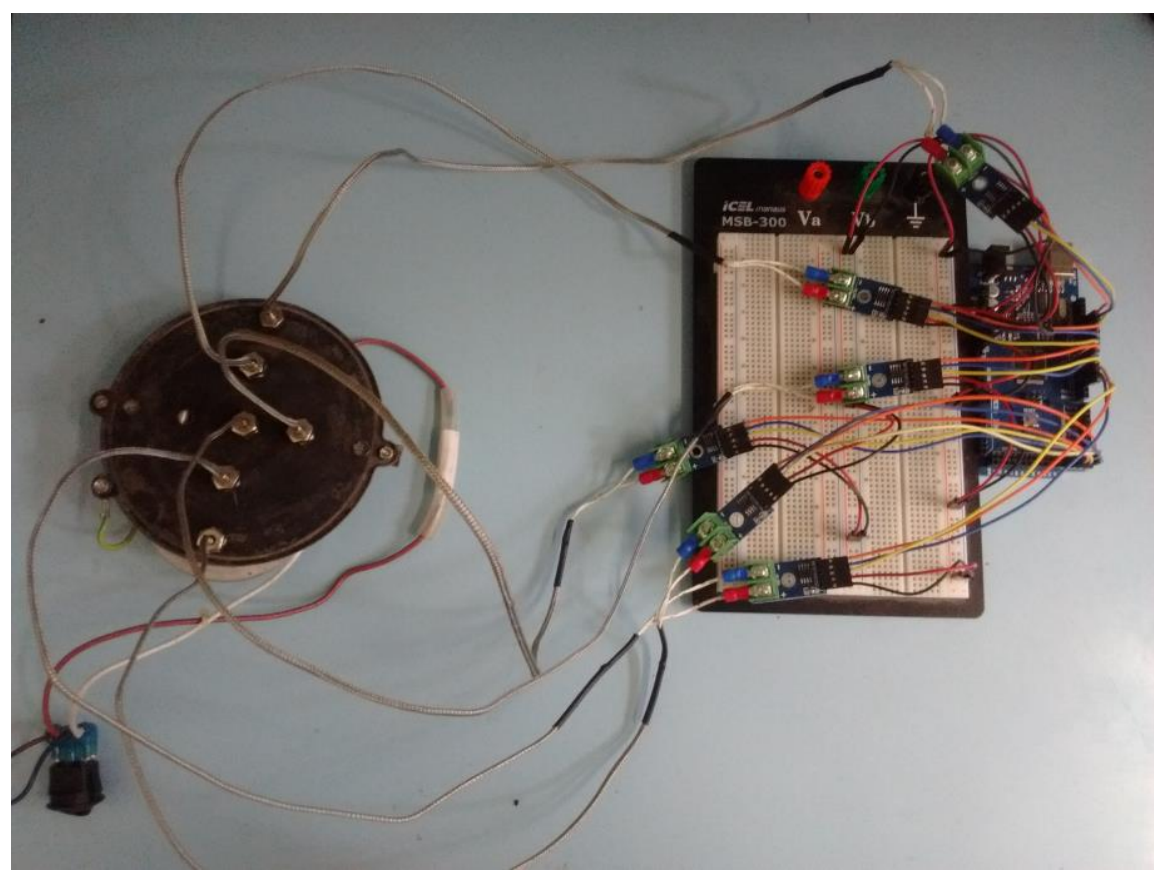

Fig. 1 - Montagem do experimento.
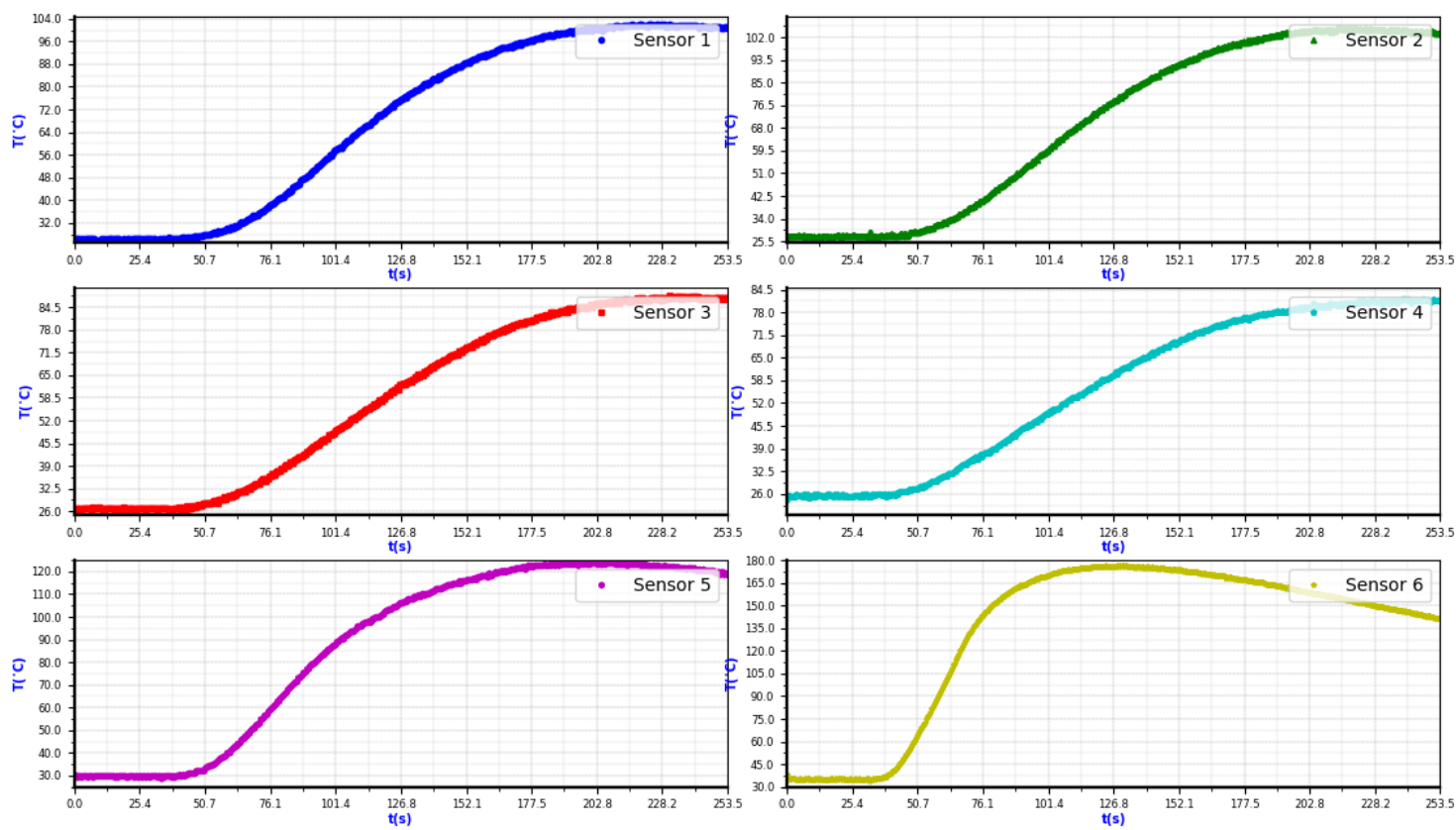

Fig. 2- Plotagem dos gráficos dos seis sensores no experimento com o circuito da cafeteira. 


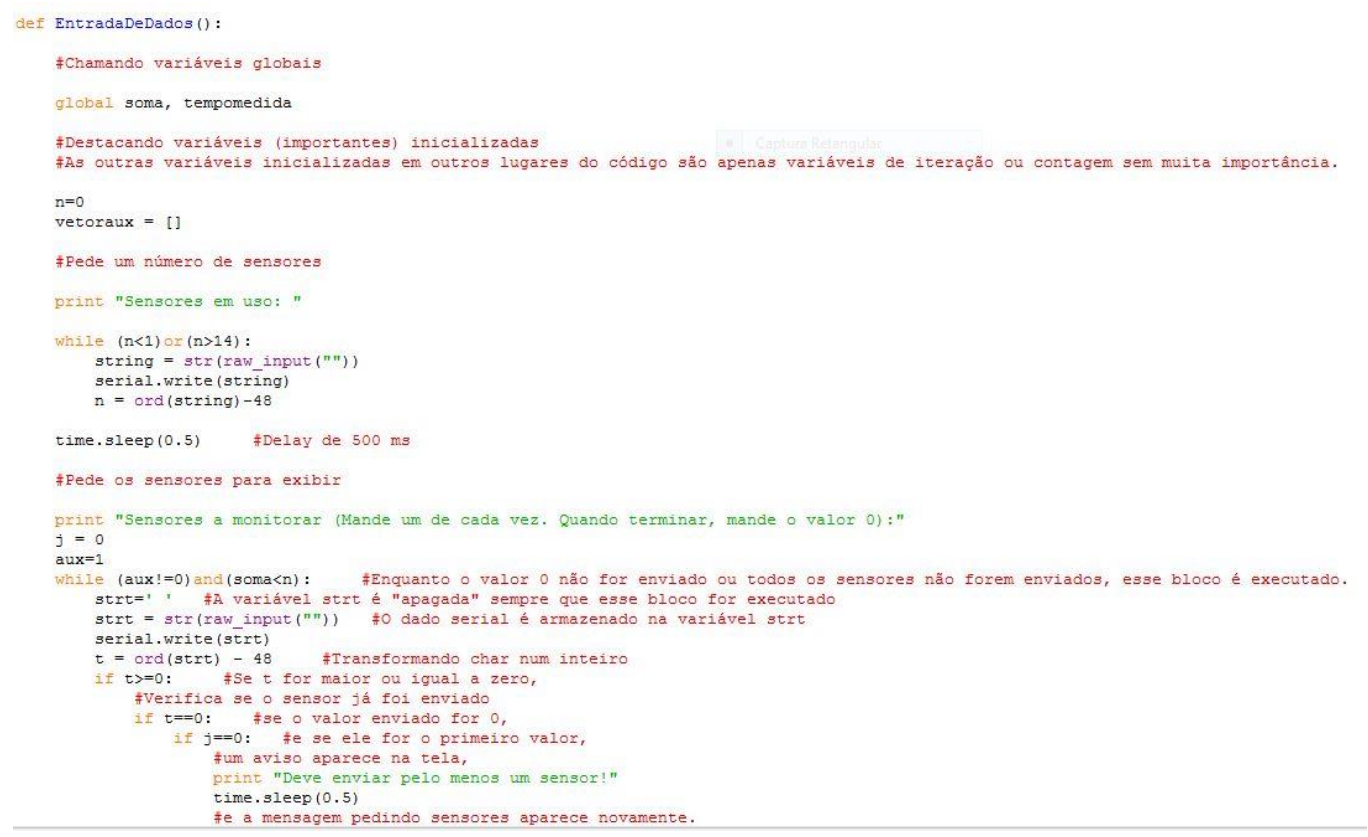

Fig. 3 - Trecho do programa.

\section{CONSIDERAÇÕES FINAIS (ou Conclusão)}

A depender da aplicação, um sistema com recurso de exibição gráfica, em tempo real, da temperatura de sensores, pode ser tão interessante e eficiente quanto um termômetro, pois ele fornece uma visualização do histórico das medidas desde o início dos experimentos. $\mathrm{O}$ sistema proposto neste trabalho pode ser implementado na fabricação de filmes finos, simplesmente fixando os sensores em pontos diversos do porta-substrato, afim de se verificar alguma condição de homogeneidade da temperatura na superfície dele, que é essencial na fabricação de filmes com dimensões amplas.

\section{REFERÊNCIAS}

MIRZAPOUR, S.; S.M. ROZATI; M.G. TAKWALE; B.R. MARATHE; V.G. BHIDE. 1994. Influence of different process parameters on physical properties of fluorine dopes indium oxide thin films. J. Mater. Sci., 29(3), 700.

STELZER, N.H.J.; J. SCHOONMAN. 1996. Materials Synthesis and Processing, 4(6), 429. Texas instruments. DATASHEET: LM35. Electronic Publication, 1999.

Maxim Integrated Products. DATASHEET: MAX6675. Electronic Publication, 2002.

OJA, I.; A. MERE; M. KRUNKS; C-H. SOLTERBECK; M. ES-SOUNI. 2004. Properties of TiO2 Films Prepared by the Spray Pyrolysis Method. Solid State Phenomena. v. 99-100. pp. 259-264.

FERREIRA, E.S. 2005. Filmes finos de brometo de tálio ( $\mathrm{TlBr}$ ) produzidos por spray pyrolysis. Universidade de São Paulo, MSc diss.

PEREDNIS, D.; L.J. GAUCKLER. 2005. Thin Film Deposition Using Spray Pyrolysis, Journal of Electroceramics, 14, 104-105. 